\title{
Silicon Carbide-Derived Carbon Prepared by Fused Salt Electrolysis and Electrochemical Performance
}

\author{
Shuyuan Wang ${ }^{1}$ and Guangjie Shao ${ }^{2}$ \\ ${ }^{1}$ School of Chemical Engineering, Hebei Normal University of Science and Technology, Qinhuangdao 066004, China \\ ${ }^{2}$ State key Laboratory of Metastable Materials Science and Technology, Yanshan University, Qinhuangdao 066004, China \\ Correspondence should be addressed to Guangjie Shao; shaogj@ysu.edu.cn
}

Received 30 March 2016; Revised 18 May 2016; Accepted 1 June 2016

Academic Editor: Pushpendra Kumar

Copyright (c) 2016 S. Wang and G. Shao. This is an open access article distributed under the Creative Commons Attribution License, which permits unrestricted use, distribution, and reproduction in any medium, provided the original work is properly cited.

\begin{abstract}
A number of carbide-derived carbon (CDC) samples were successfully synthesized by the electrolysis of SiC powder in molten $\mathrm{CaCl}_{2}$. The electrolysis was conducted at different temperatures $\left(850,900\right.$, and $\left.950^{\circ} \mathrm{C}\right)$ for $48 \mathrm{~h}$ in argon at an applied constant voltage of $3.1 \mathrm{~V}$. The structure of the resulting carbon is characterized by X-ray diffraction, Raman spectroscopy, and transmission electron microscope techniques. Cyclic voltammetry and galvanostatic charge/discharge measurements are applied to investigate electrochemical performances of the SiC-CDC material. It can be seen that the degree of order of the SiC-CDC increases monotonically along with elevation of reaction temperature, while the highest specific surface area $1137.74 \mathrm{~m}^{2} / \mathrm{g}$ together with a specific capacitance of $161.27 \mathrm{~F} / \mathrm{g}$ at a current density $300 \mathrm{~mA} / \mathrm{g}$ was achieved from sample synthesized at $900^{\circ} \mathrm{C}$.
\end{abstract}

\section{Introduction}

Carbide-derived carbon (CDC) is a new class of nanoporous material produced by selective extraction of metal atoms from the carbide crystal lattice by halogens $[1,2]$, supercritical water [3], or thermal decomposition [4]. CDC is a promising candidate for applications as electric double-layer capacitors (EDLC) [5-7], ion batteries [8,9], catalyst support [10], or storage of hydrogen [11].

Carbide-derived carbons (CDCs) made through chlorination of various metal carbides have been widely studied in recent years. However, chlorine gas is harmful to people and environment. So far, there have not been any reports on the preparation of $\mathrm{SiC}-\mathrm{CDC}$ by fused salt electrolysis method. In this paper, SiC-CDC has been prepared by fused salt electrolysis method for the first time. In contrast to the conventional routes, especially the chlorination of metal carbides, this novel method is a much easier, safer, less expensive, and more environmentally friendly process. The as-prepared CDC in this work has high purity and specific capacitance and displays a superior electrocapacitive performance.

It is well known that the property of a material is greatly dependent upon its carbon onions structure. As described in the literature, the CDC structure depends on the type of carbide precursor [12] and process parameters (e.g., temperature [13], chemical or physical activation [14], and catalysts [15]).

In this work, we have been successfully synthesized SiC$\mathrm{CDC}$ powder by the electrolysis of $\mathrm{SiC}$ powder in molten $\mathrm{CaCl}_{2}$. The effects of different electrolysis temperatures on the degree of order and electrochemical performances of silicon carbide-derived carbon were also studied in detail. The different results from literature were achieved.

\section{Experimental}

2.1. Sample Preparation. Commercially available silicon carbide ( $\mathrm{SiC}$ ) powder $(99.8 \%$, 2.5 3.5 $\mu \mathrm{m}$, Zhuzhou DeFeng Cemented Carbide Co. Ltd, China) was used as carbide precursor. The $\mathrm{SiC}$ powders were pressed into thin sheets of diameter of $8 \mathrm{~mm}$ and thickness of $1 \mathrm{~mm}$ with density of $29.86 \mathrm{~g} / \mathrm{cm}^{-3}$ under a uniaxial pressure of $10 \mathrm{MPa}$ and sintered in argon at $900^{\circ} \mathrm{C}$ for $12 \mathrm{~h}$. The sintered $\mathrm{SiC}$ thin sheets were used as the anode for electrochemical production of SiC-CDC powders. A graphite rod $(d=6 \mathrm{~mm})$ served as the cathode. A DC power supply was employed for conducting electrolysis. The $\mathrm{SiC}$ thin sheets were led to the terminal 


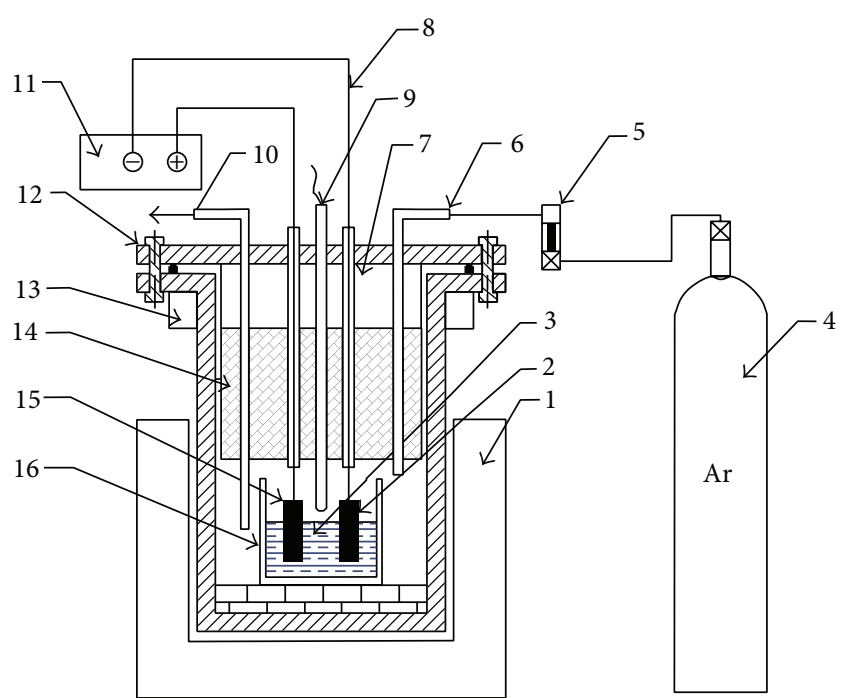

FIGURE 1: The schematic configuration of the equipment was as follows: (1) electric furnace, (2) cathode, (3) molten salt, (4) Ar gas, (5) flow meter, (6) Ar gas inlet, (7) cooling water, (8) electrode extension, (9) thermocouple, (10) Ar gas outlet, (11) regulated DC power source, (12) reactor, (13) cooling water, (14) thermal insulation layer, (15) anode, and (16) corundum crucible.

positive of the power supply. The negative terminal of the power supply was connected to the carbon cathode. Fused salt electrolysis was carried out at different temperatures for $48 \mathrm{~h}$ in argon at atmospheric pressure. The solid $\mathrm{CaCl}_{2}$ melts at the temperature $778^{\circ} \mathrm{C}$, and high temperature also results in high evaporation from the liquid $\mathrm{CaCl}_{2}$. As a result, the experimental temperatures $850^{\circ} \mathrm{C}, 900^{\circ} \mathrm{C}$, and $950^{\circ} \mathrm{C}$ were selected. The constant voltage imposed to the cells was $3.1 \mathrm{~V}$. After electrolysis, the furnace was cooled down to room temperature. The electrolytic products obtained from $\mathrm{SiC}$ anode were immersed in $1.5 \mathrm{M} \mathrm{HCl}$ for approximately $10 \mathrm{~h}$. Then, the samples were rinsed with distilled water and dried in air at $120^{\circ} \mathrm{C}$ for $12 \mathrm{~h}$.

The configuration of equipment is shown in Figure 1.

The electrolysis experiments were performed in a tubular stainless steel reactor, which was positioned vertically inside a programmable electrical furnace. A corundum crucible was filled with anhydrous calcium chloride and was heated in an argon atmosphere with a ramp rate $400^{\circ} \mathrm{C} / \mathrm{h}$ until the desired target temperature.

2.2. Characterization. The phases of the specimens were analyzed with the aid of three different techniques: (i) X-ray diffraction patterns between $10(2 \theta)$ and $100(2 \theta)$ degrees were collected by Rigaku D/MAX-2500 powder diffractometer with $\mathrm{Cu}-\mathrm{K} \alpha$ radiation $(\lambda=0.154 \mathrm{~nm})$ operated at $40 \mathrm{kV}$ and $200 \mathrm{~mA}$. (ii) Raman spectra from $100 \mathrm{~cm}^{-1}$ to $3200 \mathrm{~cm}^{-1}$ were recorded by using a Renishaw inVia Raman microscope instrument equipped with an $\operatorname{Ar}^{+}$laser $(\lambda=514.5 \mathrm{~nm})$ at $50 \mathrm{x}$ magnification $(\sim 1 \mu \mathrm{m}$ spot size) and $10 \%$ power. (iii) JEM 2010 transmission electron microscope (TEM) equipped with an imaging filter (Gatan GIF) was used at $200 \mathrm{kV}$. Specific surface area (SSA) and pore size distributions (PSD) were

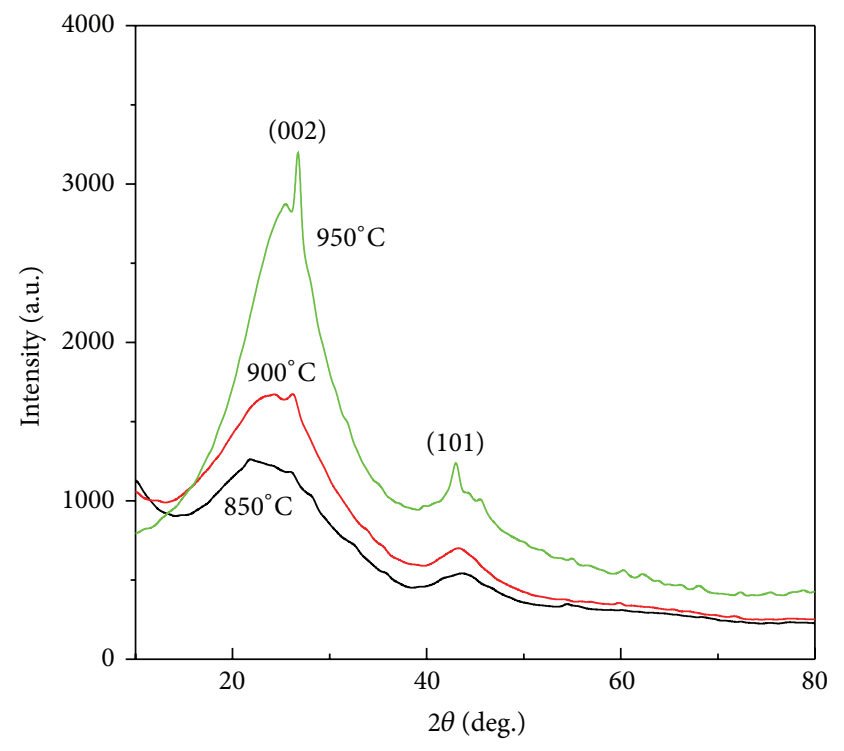

FIgURE 2: XRD patterns of the CDC electrolyzed at different temperatures of $850^{\circ} \mathrm{C}, 900^{\circ} \mathrm{C}$, and $950^{\circ} \mathrm{C}$.

tested using the specific surface snalysis (ASAP 2010 V5.03H). Electrochemical investigations were carried out in a threeelectrode cell using Platinum as counter electrode and Saturated Calomel Electrode (SCE) as reference electrode. The working electrodes were comprised of $94 \mathrm{wt} \% \mathrm{CDC}$ and $6 \mathrm{wt} \%$ Polytetrafluoroethylene (PTFE) binder (10\% suspension in water) and then pressed the slurry on a piece of foamed nickel grid whose area is $1 \times 1 \mathrm{~cm}^{2}$. The total loading mass of active materials in each working electrode is $3 \mathrm{mg}$. The electrolytes containing $0.5 \mathrm{M} \mathrm{Na}_{2} \mathrm{SO}_{4}$ were used to study the capacitive behavior of prepared electrodes. Cyclic voltammetry $(\mathrm{CV})$ studies were performed at a potential range of $-1.0 \sim-0.28 \mathrm{~V}$ versus $\mathrm{SCE}$ at scan rates $5 \mathrm{mV} / \mathrm{s}$. Galvanostatical charge-discharge tests were conducted at current densities of $300,500,1000$, and $1500 \mathrm{~mA} / \mathrm{g}$ between $-1.0 \mathrm{~V}$ and $-0.28 \mathrm{~V}$ versus SCE using cycling equipment (NEWARE, China).

\section{Results and Discussion}

The XRD patterns of the products obtained at different electrolysis temperatures are shown in Figure 2.

No peak from other compounds appears within the detection limit of XRD. It is found that the CDC from the raw $\mathrm{SiC}$ powders is mainly amorphous carbon at electrolysis temperature of $850^{\circ} \mathrm{C}$. The peaks corresponding to the graphite (002) and (101) planes at $2 \theta$ about $26.3^{\circ}$ and $43.5^{\circ}$ appear with increasing electrolysis temperatures. When the electrolysis was carried out at $950^{\circ} \mathrm{C}$, the strongly sharp peak of the graphite (002) and (101) planes indicates an increase of the degree of order. The detected peaks become sharper and stronger with increasing electrolysis temperatures, suggesting that increasing electrolysis temperatures of the $\mathrm{SiC}$ powders can improve the degree of order in the CDC.

Raman spectroscopy is a suitable method to determine the degree of order of carbon materials. Figure 3 shows 


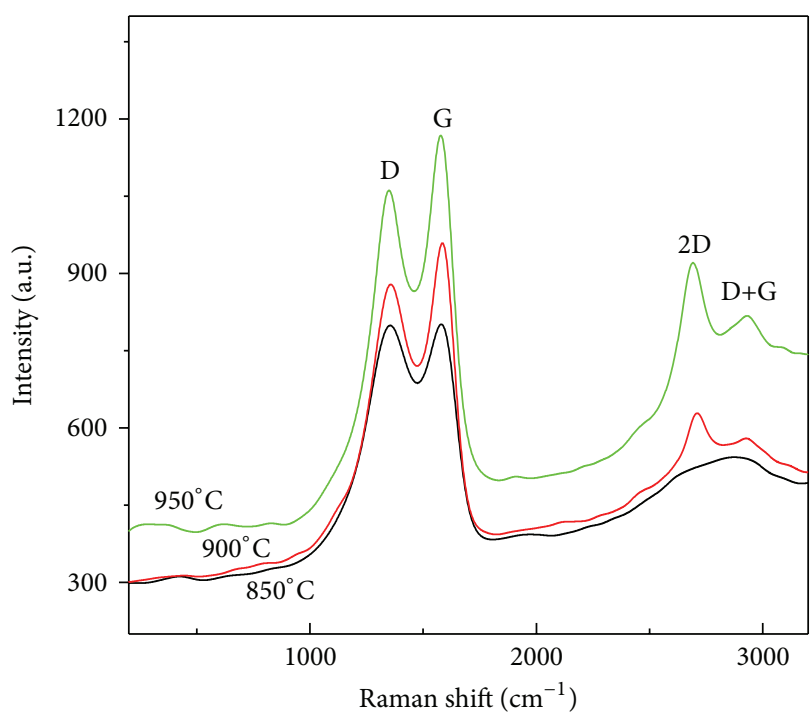

(a)

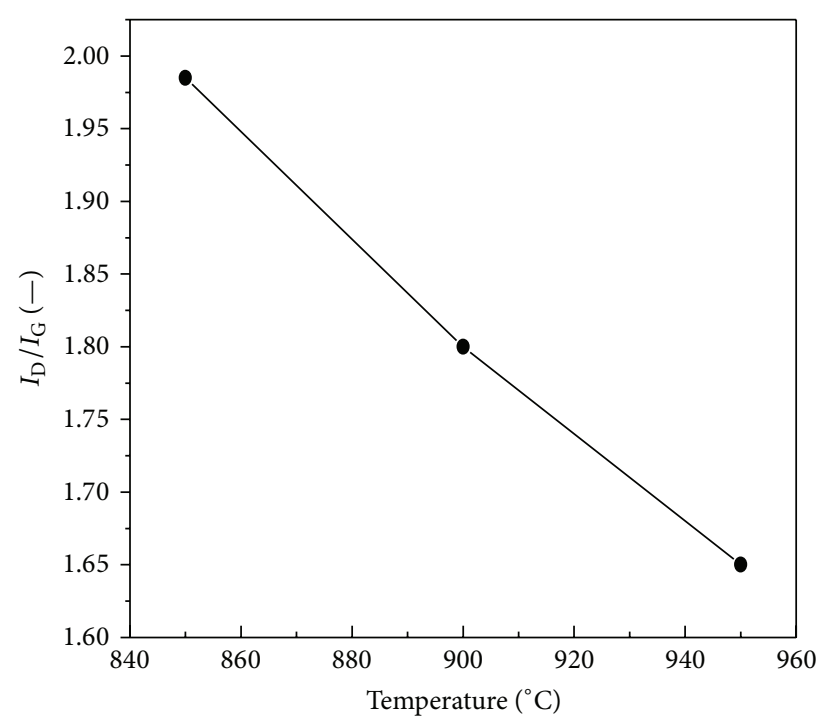

(b)

FIgURE 3: Raman spectra (a) and $I_{\mathrm{D}} / I_{\mathrm{G}}$ (b) of the CDC electrolyzed at different temperatures.

the Raman spectra of the SiC-CDC obtained at different electrolysis temperatures.

The first-order Raman spectrum features two peaks: disorder-induced peak (D-band) at wavelength $\sim 1356 \mathrm{~cm}^{-1}$ and the graphite peak (G-band) at $\sim 1580 \mathrm{~cm}^{-1}$ are detected. And they become more and more sharp with increasing electrolysis temperature from $850^{\circ} \mathrm{C}$ to $950^{\circ} \mathrm{C}$. The presence of D- and G-peaks and their intensity ratio $\left(I_{\mathrm{D}} / I_{\mathrm{G}}\right)$ can be used to extract structural information of the carbon materials. The width and intensity of these two peaks suggest the disordered nature of carbon produced from SiC-CDC. The fitted area ratio of D-band to G-band $\left(I_{\mathrm{D}} / I_{\mathrm{G}}\right)$ is 1.985 , 1.8 , and 1.65 , respectively [16]. In addition, the spectrum also shows two marked second-order peaks of the D-band (2D) at $\sim 2695 \mathrm{~cm}^{-1}$ as well as (D+G) band at $\sim 2930 \mathrm{~cm}^{-1}$ for the $\mathrm{SiC}$-CDC from electrolysis temperatures $900^{\circ} \mathrm{C}$ and $950^{\circ} \mathrm{C}$. The increase of second-order peaks is related to the ordering of the graphitic structure. Raman analysis of the samples indicates that the degree of order of SiC-CDC increases along with elevation of reaction temperature and the degree of order of this SiC-CDC is much higher than those reported CDCs in literatures [17].

The degree of order of CDC was further studied by TEM technology. Figure 4 shows TEM images of the CDCs from $\mathrm{SiC}$ powders electrolyzed at different temperatures. The images directly reflect the effect of temperature on the microstructure of CDCs. It can be seen that, in Figures 4(a) and 4(b), the CDC from the raw SiC powder electrolysis at $850^{\circ} \mathrm{C}$ is mainly amorphous carbon, and no graphitic ribbons were found. At $900^{\circ} \mathrm{C}$, along with the presence of amorphous carbon with thin sheet, the formation of some graphitic ribbons (Figures 4(c) and 4(d)) was seen obviously. As the electrolysis temperature further increases, at $950^{\circ} \mathrm{C}$ (Figures 4(e) and 4(f)), CDC contained less amorphous carbon and a large amount of highly ordered curved sheets of graphite with an interplanar distance of $0.339 \mathrm{~nm}$, which is corresponding to the interplanar spacing of (002). The images directly reflect that $\mathrm{SiC}-\mathrm{CDC}$ is a mixture of amorphous carbon and ordered graphite phase with a high degree of graphitization at higher electrolysis temperature. The TEM images are in full agreement with the XRD and Raman spectroscopy patterns.

$\mathrm{CV}$ tests were conducted to characterize the electrochemical performances of SiC-CDC. In Figure 5(a), no faradic reactions were found within the voltage window of interest for all samples. They exhibit almost rectangular shape characteristic. And the rectangular area of the $\mathrm{SiC}-\mathrm{CDC}$ electrolysis at $900^{\circ} \mathrm{C}$ is the largest among the three samples. The chargedischarge plots of the SiC-CDC were shown in Figure 5(b); as can be seen, all the charge/discharge profiles are close to an isosceles triangle, which indicates fine capacitive and revisable behaviors of the SiC-CDC. The calculated specific capacitance of synthesized samples varied with different temperatures; however, the results did not follow the trend of $I_{\mathrm{D}} / I_{\mathrm{G}}$ (Figure $3(\mathrm{~b})$ ). The highest specific capacitance of $161.27 \mathrm{~F} / \mathrm{g}$ was achieved in the sample obtained at $900^{\circ} \mathrm{C}$, which is significantly higher than $100 \mathrm{~F} / \mathrm{g}$ for conventional activated carbons and $138.3 \mathrm{~F} / \mathrm{g}, 115 \mathrm{~F} / \mathrm{g}$, and $120 \mathrm{~F} / \mathrm{g}$, the maximum specific capacitance of the samples synthesized by chlorination of carbides in literatures [18-20], and goes down to $143.04 \mathrm{~F} / \mathrm{g}$ in the sample obtained at $950^{\circ} \mathrm{C}$. The calculated energy density at the temperature of $900^{\circ} \mathrm{C}$ is $22.4 \mathrm{Wh} / \mathrm{kg}$.

It has been reported that a lot of factors of porous carbon can affect double-layer capacitance, for example, surface areas, microstructures, and pore sizes as well as pore shapes [19]. The porous structure of SiC-CDC prepared has been characterized using the low-temperature nitrogen sorption method within the relative pressure range from $10^{-7}$ to 0.95 . The specific surface area, $S_{\mathrm{BET}}$, is calculated according to Brunauer-Emmett-Teller (BET) theory, although it might not be best suited for analyzing $\mathrm{CDC}$ materials due to large errors 


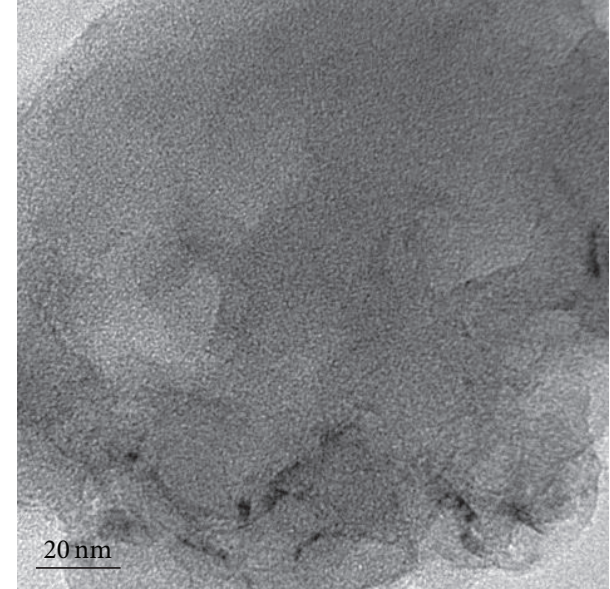

(a)

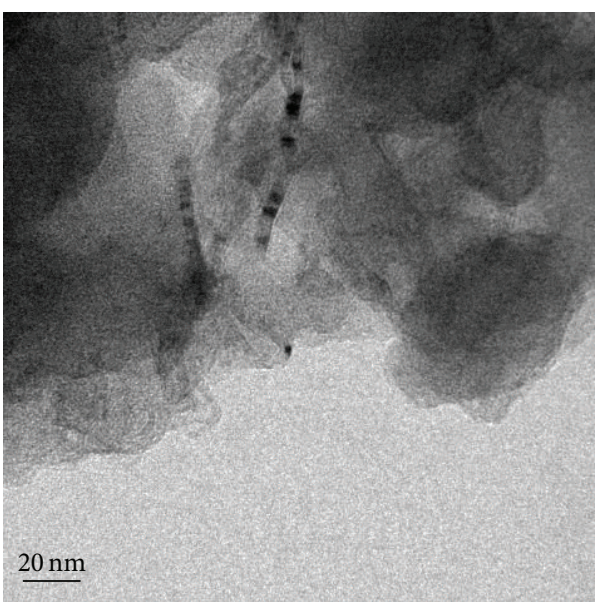

(c)

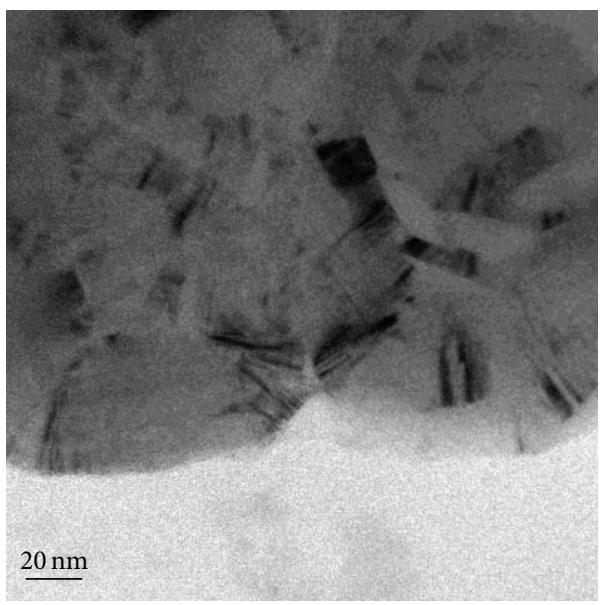

(e)

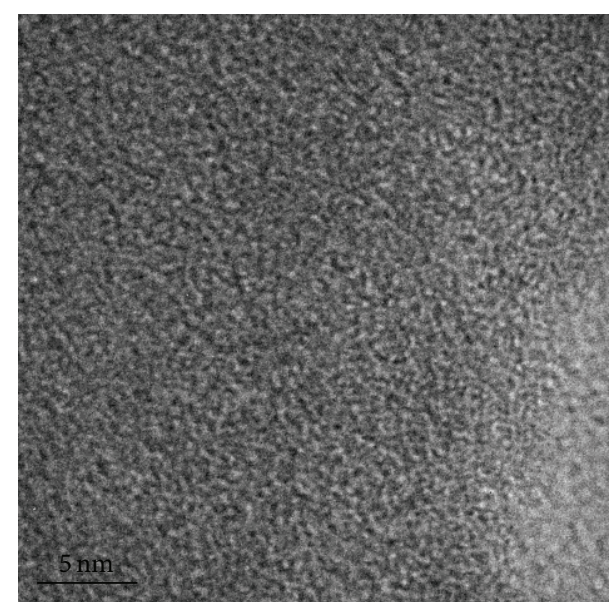

(b)

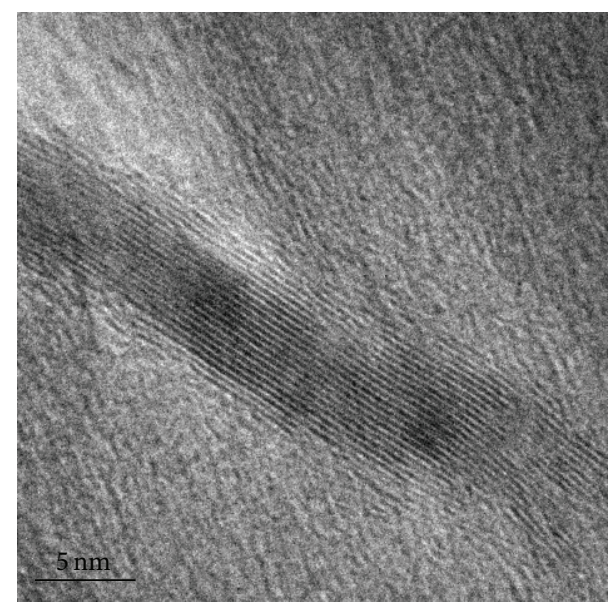

(d)

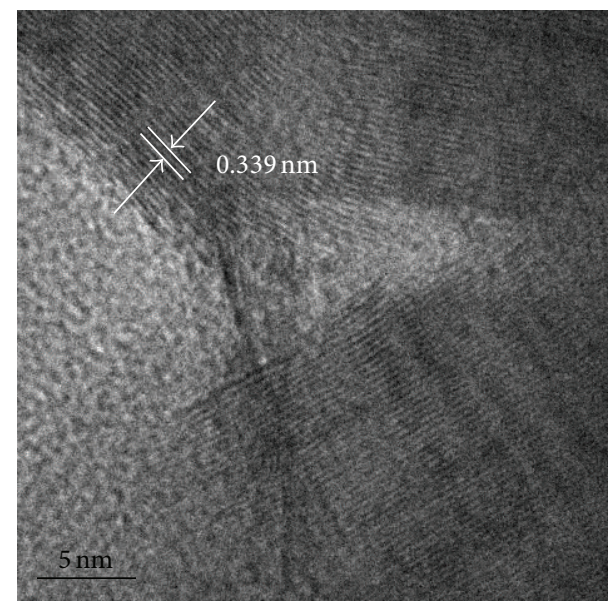

(f)

Figure 4: TEM images of the CDC: (a-b) electrolyzed at $850^{\circ} \mathrm{C},(\mathrm{c}-\mathrm{d})$ at $900^{\circ} \mathrm{C}$, and (e-f) at $950^{\circ} \mathrm{C}$.

arising from wrong parameters assumed during analysis of the data [21]. The total BET surface area for the SiC-CDC from different electrolysis temperatures $850^{\circ} \mathrm{C}, 900^{\circ} \mathrm{C}$, and $950^{\circ} \mathrm{C}$ is $763.84 \mathrm{~m}^{2} / \mathrm{g}, 1137.74 \mathrm{~m}^{2} / \mathrm{g}$, and $988.55 \mathrm{~m}^{2} / \mathrm{g}$, respectively.
The pore size distributions (Figure 6) of the samples have been calculated applying Horvath-Kawazoe theory. It indicates the coexistence of micropores (pore $<2 \mathrm{~nm}$ ) and mesopores (pores in between 2 and $50 \mathrm{~nm}$ ) in these SiC-CDCs. In addition, we also notice that the $\mathrm{SiC}-\mathrm{CDC}$ synthesized 


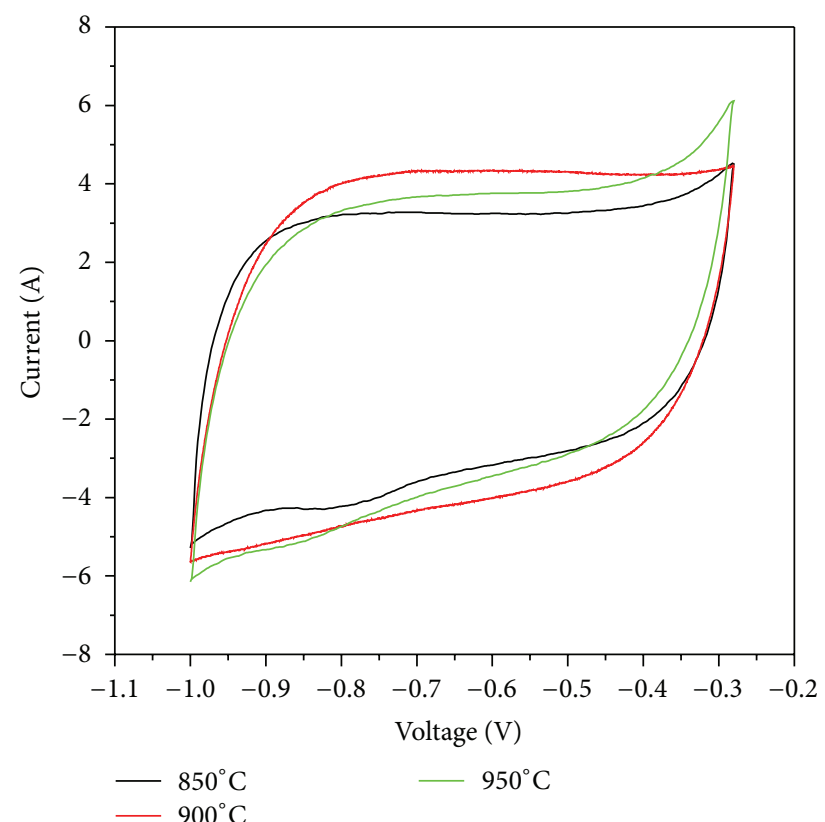

(a)

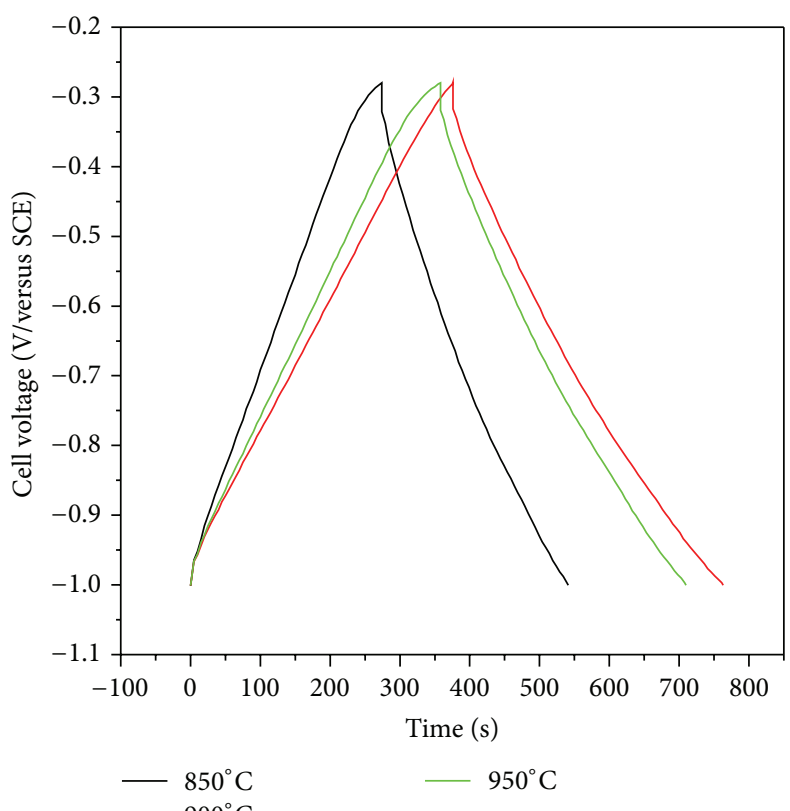

(b)

Figure 5: (a) Cyclic voltammogram of SiC-CDC electrolyzed at different temperatures with sweep rate of $5 \mathrm{mV} / \mathrm{s}$; (b) charge-discharge curves measured at $300 \mathrm{~mA} / \mathrm{g}$.

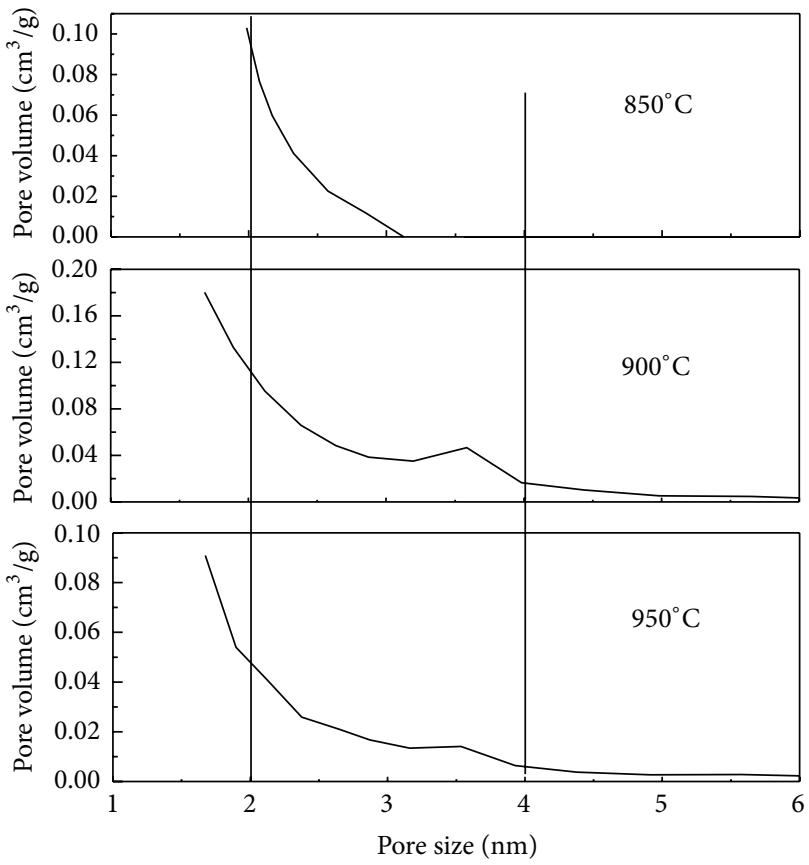

FIgure 6: Pore size distributions of SiC-CDC electrolyzed at different temperatures.

at electrolysis temperature $900^{\circ} \mathrm{C}$ has the highest proportion of pore volume and micropores in three samples. The high proportion micropores in the CDC help to enhance doublelayer capacitance [17]. As a result, the sample synthesized at electrolysis temperature $900^{\circ} \mathrm{C}$ exhibits the largest specific surface area and the highest specific capacitance.

\section{Conclusions}

The SiC-CDC has been successfully synthesized by electrolysis of $\mathrm{SiC}$ powder in molten $\mathrm{CaCl}_{2}$. This method to produce $\mathrm{SiC}-\mathrm{CDC}$ is a much easier, safer, less expensive, and more environmentally friendly process. The as-prepared CDC has much higher purity and specific capacitance and displays a superior electrocapacitive performance.

We also studied the effects of different electrolysis temperatures on the degree of order and electrochemical performance of SiC-CDC. It is demonstrated that the degree of order of the SiC-CDC increases monotonically along with elevation of reaction temperature, and the highest degree of order occurs at the electrolysis temperature $950^{\circ} \mathrm{C}$. The highest specific capacitance of $161.27 \mathrm{~F} / \mathrm{g}$ at a current density $300 \mathrm{~mA} / \mathrm{g}$ was achieved from the sample synthesized at $900^{\circ} \mathrm{C}$, which is significantly higher than the chlorination of carbides synthesized samples. This improved design provides a more economic way to produce CDC with good specific supercapacity.

\section{Competing Interests}

The authors declare that they have no competing interests.

\section{References}

[1] I. Tallo, T. Thomberg, K. Kontturi, A. Jänes, and E. Lust, "Nanostructured carbide-derived carbon synthesized by chlorination of tungsten carbide," Carbon, vol. 49, no. 13, pp. 4427-4433, 2011.

[2] P. González-García, E. Urones-Garrote, E. del Corro, D. ÁvilaBrande, and L. C. Otero-Díaz, "The production of carbon 
particles of different shapes produced by the chlorination of $\mathrm{Cr}\left(\mathrm{C}_{5} \mathrm{H}_{5}\right)_{2}$," Carbon, vol. 52, pp. 90-99, 2013.

[3] Y. G. Gogotsi, P. Kofstad, M. Yoshimura, and K. G. Nickel, "Formation of sp3-bonded carbon upon hydrothermal treatment of SiC," Diamond and Related Materials, vol. 5, no. 2, pp. 151-162, 1996.

[4] S. Iijima, "Graphitization of silicon carbide due to electron beam irradiation," Journal of Solid State Chemistry, vol. 42, no. 1, pp. 101-105, 1982.

[5] P. Simon and Y. Gogotsi, "Materials for electrochemical capacitors," Nature Materials, vol. 7, no. 11, pp. 845-854, 2008.

[6] M. Inagaki, H. Konno, and O. Tanaike, "Carbon materials for electrochemical capacitors," Journal of Power Sources, vol. 195, no. 24, pp. 7880-7903, 2010.

[7] W. Li, D. Chen, Z. Li et al., "Nitrogen enriched mesoporous carbon spheres obtained by a facile method and its application for electrochemical capacitor," Electrochemistry Communications, vol. 9, no. 4, pp. 569-573, 2007.

[8] C. Li, X. Yin, L. Chen, Q. Li, and T. Wang, "Porous carbon nanofibers derived from conducting polymer: synthesis and application in lithium-ion batteries with high-rate capability," The Journal of Physical Chemistry C, vol. 113, no. 30, pp. 1343813442, 2009.

[9] L. Ji and X. Zhang, "Fabrication of porous carbon/Si composite nanofibers as high-capacity battery electrodes," Electrochemistry Communications, vol. 11, no. 6, pp. 1146-1149, 2009.

[10] D. A. Ersoy, M. J. McNallan, and Y. Gogotsi, "Platinum reactions with carbon coatings produced by high temperature chlorination of silicon carbide," Journal of the Electrochemical Society, vol. 148, no. 12, pp. C774-C779, 2001.

[11] R. Dash, J. Chmiola, G. Yushin et al., "Titanium carbide derived nanoporous carbon for energy-related applications," Carbon, vol. 44, no. 12, pp. 2489-2497, 2006.

[12] M. Kormann, H. Gerhard, and N. Popovska, "Comparative study of carbide-derived carbons obtained from biomorphic TiC and SiC structures," Carbon, vol. 47, no. 1, pp. 242-250, 2009.

[13] C. Portet, D. Kazachkin, S. Osswald, Y. Gogotsi, and E. Borguet, "Impact of synthesis conditions on surface chemistry and structure of carbide-derived carbons," Thermochimica Acta, vol. 497, no. 1-2, pp. 137-142, 2010.

[14] M. Kormann and N. Popovska, "Processing of carbide-derived carbons with enhanced porosity by activation with carbon dioxide," Microporous and Mesoporous Materials, vol. 130, no. 1-3, pp. 167-173, 2010.

[15] M. Kormann, H. Gerhard, C. Zollfrank, H. Scheel, and N. Popovska, "Effect of transition metal catalysts on the microstructure of carbide-derived carbon," Carbon, vol. 47, no. 10, pp. 2344-2351, 2009.

[16] J. Ribeiro-Soares, L. G. Cançado, N. P. S. Falcão, E. H. Martins Ferreira, C. A. Achete, and A. Jorio, "The use of Raman spectroscopy to characterize the carbon materials found in Amazonian anthrosoils," Journal of Raman Spectroscopy, vol. 44, no. 2, pp. 283-289, 2013.

[17] A. Jänes, T. Thomberg, and E. Lust, "Synthesis and characterisation of nanoporous carbide-derived carbon by chlorination of vanadium carbide," Carbon, vol. 45, no. 14, pp. 2717-2722, 2007.

[18] Y. Zhao, W. Wang, D.-B. Xiong et al., "Titanium carbide derived nanoporous carbon for supercapacitor applications," International Journal of Hydrogen Energy, vol. 37, no. 24, pp. 19395-19400, 2012.
[19] E. Tee, I. Tallo, H. Kurig, T. Thomberg, A. Jänes, and E. Lust, "Huge enhancement of energy storage capacity and power density of supercapacitors based on the carbon dioxide activated microporous SiC-CDC," Electrochimica Acta, vol. 161, pp. 364370, 2015.

[20] T. Ariyanto, A. M. Laziz, J. Gläsel, G.-R. Zhang, J. Garbes, and B. J. M. Etzold, "Producing high quality carbide-derived carbon from low quality byproducts stemming from SiC production," Chemical Engineering Journal, vol. 283, pp. 676-681, 2016.

[21] F. Stoeckli and T. A. Centeno, "On the determination of surface areas in activated carbons," Carbon, vol. 43, no. 6, pp. 1184-1190, 2005. 

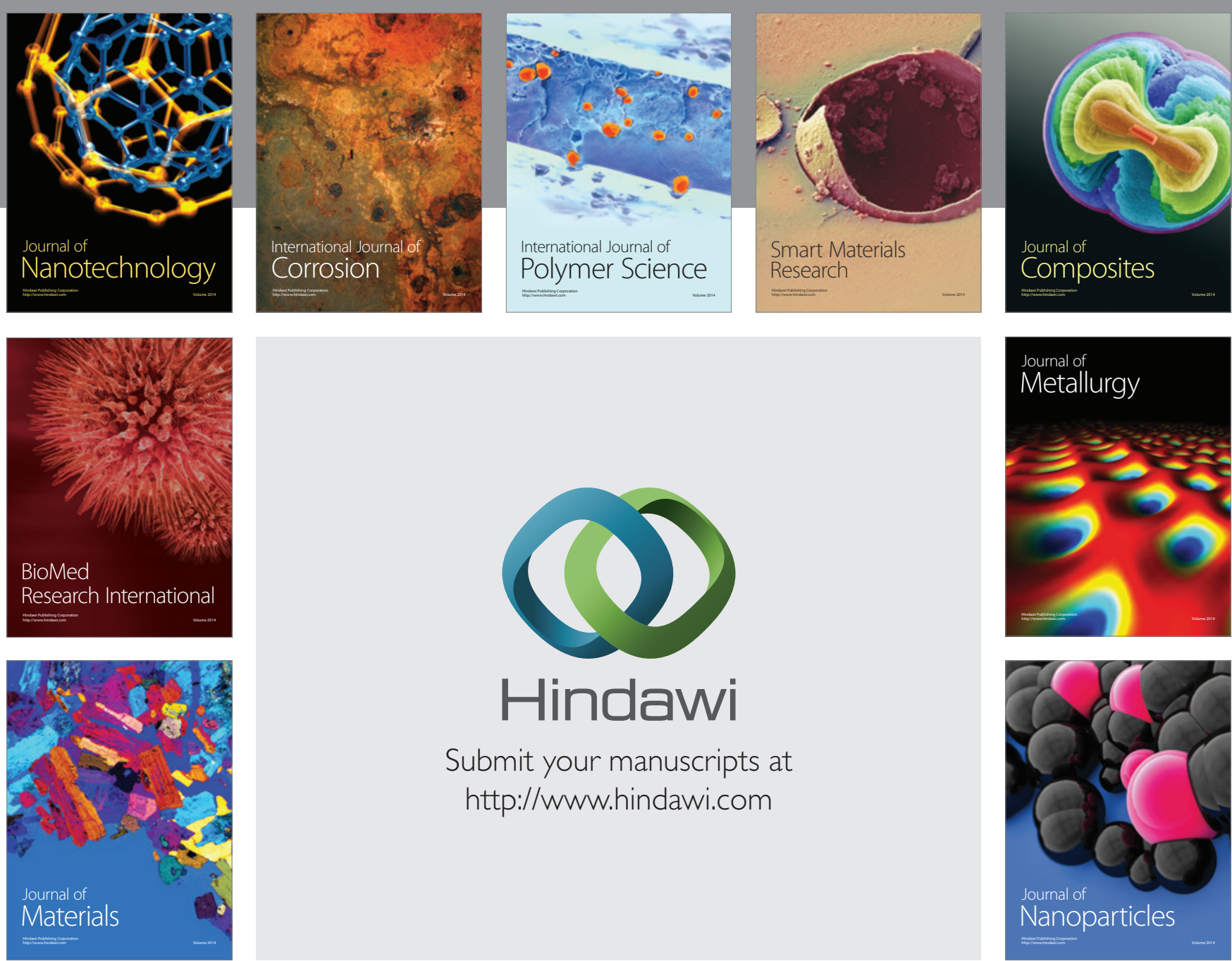

\section{Hindawi}

Submit your manuscripts at

http://www.hindawi.com

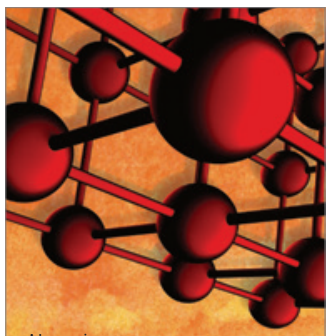

Materials Science and Engineering
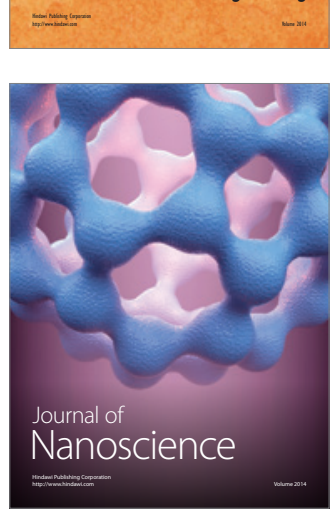
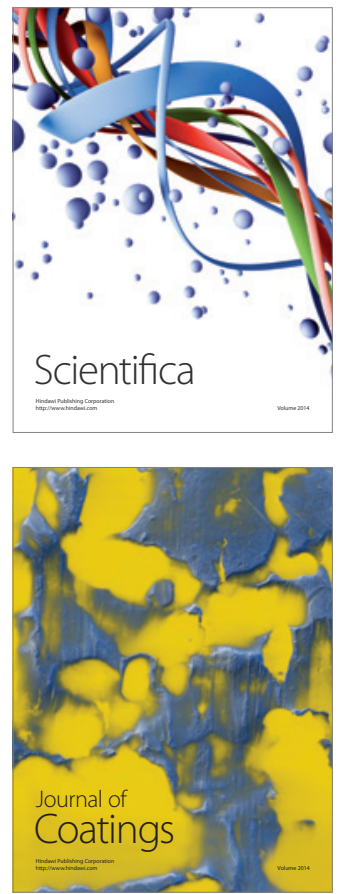
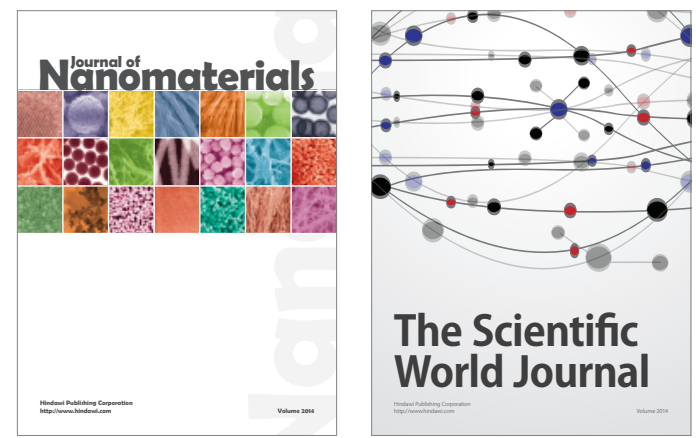

The Scientific World Journal
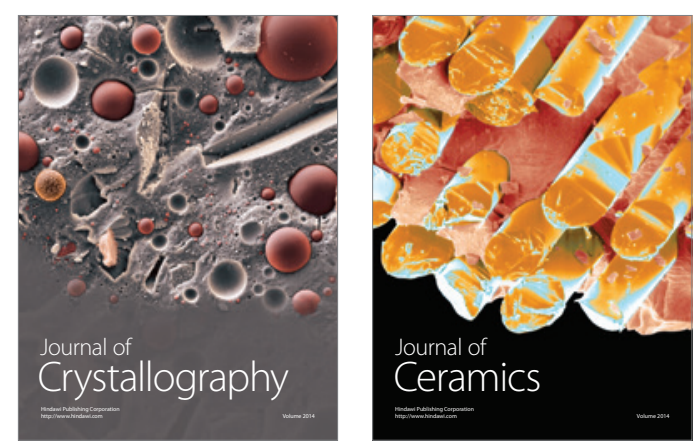
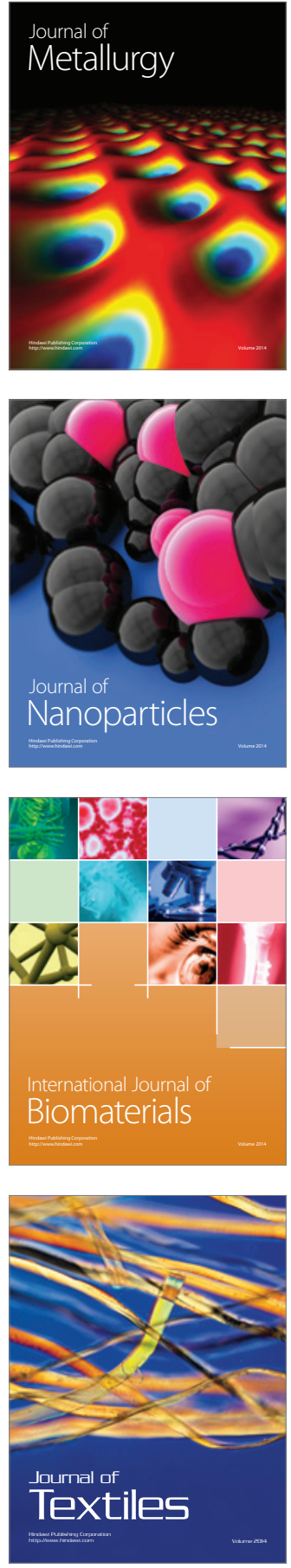